\title{
Maternal and paternal contribution to intergenerational psychosocial transmission of paan chewing.
}

Sreenath A Madathil ${ }^{\mathrm{a}, \mathrm{b}}$, Marie-Claude Rousseau ${ }^{\mathrm{a}, \mathrm{b}}$, Paul Allison ${ }^{\mathrm{a}}$, Gopalakrishnan Netuvelic, Gerald M. Humphris ${ }^{\mathrm{d}}$, Ipe Varghese ${ }^{\mathrm{e}}$, Shameena Shiraz ${ }^{\mathrm{f}}$, Genevieve Castonguay ${ }^{\mathrm{a}}$, Akhil-Soman Thekkepurakkal $^{\mathrm{a}}$, Hameed P. Shahul ${ }^{\mathrm{a}}$, Belinda Nicolau ${ }^{\mathrm{a}^{*}}$

a. Division of Oral Health and Society, Faculty of Dentistry, McGill University, 2001 McGill College Avenue, Suite 500, Montreal, Quebec, H3A1G1, Canada.

b. Epidemiology and Biostatistics Unit, INRS-Institut Armand-Frappier, 531 boul. Prairie, Laval, Quebec, H7V1B7, Canada.

c. Institute of Health and Human Development, UH250 Startford Campus, University of East London, Water Lane, London, E154LZ, UK;

d. School of Medicine, North Haugh, University of St Andrews, Fife, KY16 9TF, UK;

e. Kerala University of Health Sciences, Medical college PO, Thrissur, Kerala, 680596, India;

f. Oral pathology, Government Dental College, Medical College Campus, Kozhikode 8, Kerala, India.

*Corresponding author at:

Dr. Belinda Nicolau

Associate Professor

Division of Oral Health and Society

Faculty of Dentistry

McGill University

2001 McGill College Avenue, Suite 500

Montreal, Quebec, Canada

H3A 1G1

Email:belinda.nicolau@mcgill.ca

Tel: 514-3987203 ext. 094655

Fax: 514-3987220

DOI: $\underline{10.1111 / \text { cdoe. } 12153}$ 


\section{ABSTRACT:}

Objectives: Paan chewing is a recognized risk factor for oral cancer in the Asian population. However, there is currently little evidence about the intergenerational psychosocial transmission of paan chewing in South Indian families. We investigated the association between parental and participant's paan chewing in a South Indian population.

Methods: A subset of data was drawn from a hospital-based case-control study on oral cancer, the HeNCe Life study, conducted at Government Dental and Medical Colleges of Kozhikode, South India. Analyses were based on 371 non-cancer control participants having diseases unrelated to known risk factors for oral cancer. Demographics, behavioural habits (e.g., paan chewing, smoking), and indicators of socioeconomic position (SEP) of both participants and their parents were collected with the use of a questionnaire-based interview and a life grid technique. Unconditional logistic regression assessed odds ratios (OR) and 95\% confidence intervals $(95 \% \mathrm{CI})$ for the associations between parental and participant's paan chewing, adjusted for confounders.

Results: Over half of the participants were male (55.2\%) and the mean age of participants was 59 (SD=12) years. After adjusting for age, religion, parents' SEP, parents' education, smoking and alcohol consumption, and perceived parenting behaviour we observed that maternal and paternal paan chewing were significantly associated with the participant's paan chewing $(\mathrm{OR}=2.40,95 \% \mathrm{CI}=1.11-5.21)$ and $(\mathrm{OR}=3.05,95 \% \mathrm{CI}=1.48-6.27)$, respectively.

Conclusions: Intergenerational psychosocial transmission of the habit of paan chewing could occur through shared socio-cultural or environmental factors.

Keywords: Intergenerational relation; betel quid chewing; lifecourse 


\section{INTRODUCTION}

Tobacco use, a well-established etiological factor for oral cancer, is a highly prevalent habit in India. By 2030, mortality related to this habit is expected to rise to more than 8.3 million globally (1). Smokeless tobacco is the most common form of tobacco use practiced by over $26 \%$ of the Indian population (2). Paan (betel quid with or without tobacco) is one of the most prevalent forms of smokeless tobacco, with 49.7 million (8\%) users in the country (2). Although the components of paan may vary according to geographical area, it is usually a mixture of areca nut (from the areca catechu tree), slaked lime (calcium hydroxide) with or without tobacco, wrapped in a piper betel leaf (3). The prevalence of paan chewing, the strongest oral cancer risk factor in India, is increasing among the youth in this population (4). The International Agency for Research on Cancer (IARC) has classified betel quid with or without tobacco as a human carcinogen (Group 1) (3).

Several theories have been put forward to explain the way in which parents can influence their children's behaviour. The social learning theory argues that learning occurs within a social context where people observe and imitate each other's behavior. As children grow up, their most important social context is constituted by the family which makes parents the most influential people in a child's socialization process $(5,6)$. Children observed and copy their parents' behaviour. Through generations, these mechanisms help to develop a shared cultural intelligence, which determines acceptable and unacceptable behaviors in a society (7). Social learning theory has been used to explain many characteristics of accruing moderate to high risk social behaviors including smoking, alcohol abuse and deviant behaviors $(8,9)$.

A recent systematic review on the social context of smokeless tobacco use showed that the mean age of initiation in the South Asian population was 15 years. Reasons for starting the habit included social and cultural acceptance, low cost and easy availability, peer pressure, taste, and mental relaxation effects (10). In addition, the most common social context of tobacco chewing was paan use by family members. Qualitative studies have also shown the cultural acceptability of the habit (10). Although parental influence and the contribution of parenting behaviour patterns to smoking $(8,11-14)$ and alcohol habits $(13,15-20)$ have been widely investigated, the intergenerational transmission of the paan chewing habit has received less attention (21-24). In addition, most of the studies have marked methodological limitations. For example, they are limited to descriptive analyses and often use a simplified conceptual framework without accounting for potential confounders (21-24). Furthermore, none of these studies has explored how parenting behaviors can modify the association between parental paan chewing and their offspring's paan chewing, which is considered crucial in mediating intergenerational continuity of risk taking behaviors (25). Lastly, none of the previous studies has separately investigated maternal and paternal habits. Unlike Western cultures, where most of these studies were conducted, India has more interdependent family dynamics with a highly patrilineal society (26). Therefore, it is important to understand the gender roles in this transmission. In this paper, we investigate the extent to which subject's father and mother paan chewing habits is associated with their own paan chewing behaviour. Furthermore, we explore whether this association is explained by parenting behaviour patterns.

\section{MATERIALS AND METHODS}

\subsection{Study design}

This paper uses data collected from the control participants of a hospital-based case-control study investigating the etiology of cancer in the upper aero digestive tract. In brief, the Head and 
Neck Cancer Etiology (HeNCe) Life Study was conducted at the Government Dental and Medical Colleges of Kozhikode, South India from 2008 to 2012. Cases were newly diagnosed and histologically confirmed oral squamous cell carcinoma $(n=350)$. Control participants were non-cancer subjects $(n=371)$ recruited from outpatient clinics of the same institutions as the cases, and were frequency-matched to cases by age and sex.

The eligibility criteria were: (i) to be born in India; (ii) to be at least 18 years of age; (iii) to live within $150 \mathrm{~km}$ of the hospital area; and (iv) to have no previous history of cancer or HIV infection. The study was approved by the Institutional Review Board of all participating institutions.

\subsection{Data collection}

After obtaining informed consent, trained dentists collected information during a questionnairebased interview using a life grid technique (27). Fieldwork operations, including the research instruments, were tested in a pilot study conducted during 2007-2008, and modifications were made accordingly. Detailed information was collected on indicators of socioeconomic position (SEP), psychosocial, and behavioural factors along the participant's life span. For subjects who had difficulty speaking due to their disease (14.3\% cases, 3.5\% controls), interviews were conducted with the help of a proxy, usually a close family member.

\subsection{Data reduction for perceived parenting behaviors}

Participants' perception of their mother's and father's parenting behaviors were recorded using a modified version of the parental bonding instrument (28) (7 questions), adapted from the Whitehall II study (29). Internal consistency of these questions was assessed using Cronbach's alpha value. To identify the latent constructs measured by these questions, an exploratory factor analysis was carried out separately for maternal and paternal parenting behaviors. An oblimin rotation with delta 0 was applied and factors with an Eigenvalue $>1$ were retained. Two latent constructs of subject's perception of parenting behaviors were identified for each parent, resulting in four variables: maternal warmth, maternal strictness, paternal warmth and paternal strictness. Four questions regarding understanding, loving, affectionate and trustworthy behaviour of the parent loaded on the 'warmth' factor, and two questions regarding punishment and rules loaded on the 'strictness' factor. For better interpretability of the scores, the questions were combined based on their factor loadings (refer to supplementary material). Higher scores indicate higher parental warmth or strictness.

\subsection{Statistical analysis}

Information on each parent's paan chewing was collected as 'never' or 'ever chewer' of paan (at least one year of habit history). Participant's complete history of paan chewing was collected. The presence or absence of the habit was considered as the outcome of interest, where at least one year of paan chewing was used to classify subjects as 'ever chewers'. Level of education was collected as years of education, and then categorized based on the historical context of Kerala, the study site (30). For participants born until 1950, more than four years of formal education was considered as a high educational attainment, whereas the same category was attributed to those with more than eight years of formal education for participants born after 1950.

Lifetime history of smoking and alcohol consumption was collected, and later categorized as “never” or “ever user”. Parent's SEP was assessed using 9 questions about participant's 
childhood material adversities (housing conditions and amenities). Further, responses to each question were dichotomized, considering the presence or absence of amenities (e.g., toilet inside the house) and type of house building material denoting high or low material deprivation. These variables were then combined into an index by adding the scores of material deprivation, resulting in values ranging from 0 to 9. The index was further categorized into low and high SEP using the median as a cut-off point.

Fifty-one (16\%) participants had missing values in maternal or paternal education and one subject had missing information for paternal paan chewing. Multiple imputation by chained equation (MICE) was carried out to impute missing values; 20 imputed data sets were generated and "Rubin's rules" were applied to combine estimates of interest across the imputed data sets (31). The missing value for paternal paan chewing was not imputed; this subject was excluded from the analysis.

Causal diagrams are a visual representation of the causal relationships between variables in a source population. Directed acyclic graphs (DAG) are a type of causal diagram introduced by Pearl in 1995 (32). DAGs based on a priori knowledge are widely used to help plan data collection and analysis, in communicating results and to avoid pitfalls when selecting confounders $(33,34)$. We used DAGs to identify the minimum set of confounders to be taken into account to estimate the true association between parental and participant's paan chewing (Supplementary material Figure S3). Figure 1 present a simplified conceptual model of associations of interest informed from DAGs. Age, religious beliefs, parents' SEP, and perceived parenting behaviour were identified as the minimum set of potential confounders, to be included in the multivariate analyses. Further, to distinguish the effect of maternal and paternal paan chewing, they were mutually adjusted for one another in the corresponding models.

Data analyses included descriptive statistics and unconditional logistic regression to estimate odds ratios (OR) and 95\% confidence intervals (95\%CI) for the associations between parental and participant's paan chewing. All analyses were carried out using STATA-12 (StataCorp LP, College Station, Texas, USA) (35). Because the hypothesized psychosocial transmission of paan chewing from parents to participants assumes that the participants were raised by their parents during childhood through adolescence, subjects who reported that they were not brought up by their parents $(n=52,14.0 \%)$, were excluded from the analysis resulting in a final sample of 318 people.

\section{RESULTS}

We explored the representativeness of the final sample by comparing our results to a recently published survey published on the source population (Table 1). The prevalence of paan chewing in both samples was similar, denoting adequate representation in regard to the exposure of interest. Table 2 displays the frequency distribution of selected variables in our sample. Participants' age ranged from 29 to 89 years with a mean age \pm SD of $59.86 \pm 11.8$ years (Table 2 ). More than $55 \%$ of the participants were males and $52(16.3 \%)$ reported the habit of paan chewing for at least one year. The majority were Hindus (61.0\%) and literate (86.2\%). Parental paan chewing was more prevalent among participants who were paan chewers: $76.9 \%$ and $61.5 \%$ of paan chewers reported that their mother and father had the habit, respectively (Table 3).

In the model without adjusting for parental bonding variables, maternal and paternal paan chewing was significantly associated with participant's paan chewing [(OR= 2.66, 95\%CI: 1.25 - 5.65) and $(\mathrm{OR}=2.93$, 95\%CI: 1.44 - 5.95)] respectively (Table 3). In the model which considered parental bonding variables, even after adjusting for the paternal paan chewing, 
subjects who had mothers with the paan chewing habit were 2.4 times more likely to adopt the habit compared to subjects whose mothers were not paan chewers [OR=2.40,95\%CI: 1.11 5.21]. Similarly, after adjusting for maternal paan chewing, subjects who had fathers with the habit of paan chewing were 3 times more likely to be chewers compared to others [OR=3.05,95\% CI: 1.48 - 6.27] (Table 3). Perceived maternal strictness was marginally significantly associated with the participants' habit of paan chewing [OR=1.34, 95\% CI: $1.05-$ $1.70]$, whereas perceived maternal warmth had only a marginally significant effect $[\mathrm{OR}=1.15$, 95\% CI: $0.97-1.35]$. Perceived paternal warmth and strictness were not significantly associated with the participants' habit of paan chewing ([OR=1.05, 95\% CI: $0.93-1.18]$ and [OR= 1.00, 95\%CI: $0.80-1.27$ ] respectively).

\section{DISCUSSION}

This study investigates the associations between parental and participant's paan chewing habits, and explores whether this association is explained by parental behaviour. In doing so, this study adds to the literature by examining psychosocial intergenerational risk transmission in relation to paan chewing. This topic has been widely studied in the Western world with regard to transmission of alcohol abuse, smoking, adolescent delinquency and other anti-social behaviors, where parenting styles have been proposed to have a mediating and reinforcing effect $(8,12,13,17,18,29,36)$. Our results suggest that maternal and paternal habit of paan chewing have an effect on the participant's habit among subjects attending outpatient clinics of hospitals located in Kerala. Moreover, maternal and paternal contributions to the intergenerational risk transmission were similar. However, maternal strictness was significantly associated with participants' habit of paan chewing even after adjusting for maternal paan chewing. Other measures of parental behaviors were not significantly or only marginally associated with the participant's habit of paan chewing.

Although a hospital-based study design limits the external validity of our results, our sample was representative of the source population in regard to paan chewing habit based on a recent population survey (Table 1) (2). There was only a single level of measurement in our study that is, participants described their parents' habits; it was not reported by the parents themselves. This could be considered as a limitation of our study. However, there is no reason to believe that the participants will report the parental habit differently than their own except for recall bias. Our study adopted extensive measures to reduce recall bias with the help of a life grid technique to collect data within a life course framework (27).

Cross-sectional study results have lower potential in explaining causality or association due to difficulty in establishing the temporal sequence of events, but there is no reason to expect that the current paan chewing status of the participant could result in differential recall of their parents' habit. Even though biological causality cannot be judged, what is more meaningful from a knowledge translation point of view is that our results show the psychosocial risk for an intergenerational continuity of the paan chewing habit in a subgroup of individuals. This intergenerational continuity may result from a process by which one generation leads the subsequent generation to a disadvantaged life trajectory (25).

Biological influence through genetic effects kept aside, the parent and offspring may have multiple shared social, cultural, lifestyle and environmental experiences which kick start the cycle of risk taking behaviors through generations.

To our knowledge this is the first study to empirically investigate the association between perceived parental behaviors and participant's habit of paan chewing in India. One aspect of this 
relationship is the parenting style. Although our questionnaire is validated and derived from the parental bonding instrument (29), it was not specifically designed to measure parenting style. Nevertheless, it can provide insights into this important aspect of parent-child relationships. The mediation role of parenting styles has been well documented in the intergenerational continuity of smoking and alcohol $(19,21,37,38)$. Most studies were conducted in Western populations, where authoritative parenting style is more common which allows the child greater independence. However, the authoritarian parenting style is more common in India, which is less flexible and includes strong discipline practices (26).

Socio-cultural context and family dynamics in India differ from those in the Western world. Indian families are more interdependent compared to the Western autonomous lifestyle (39). Child rearing practices are also different; more parental control is considered as protection rather than constraint (26), and discipline practices extend to a social acceptance of corporal punishment (spanking and slapping) (40). In a hierarchical society such as India, there is a strict adherence to gender roles where a notion of a strict father and a kind mother has been documented (41). This observation supports our results showing that maternal strictness, which included questions on punishment and enforcement of rules, is significantly associated with the participant's habit of paan chewing. High maternal strictness may have negatively affected the child's psycho-social development contributing to paan chewing later in life.

Research has proposed a conceptual framework exploring reasons for starting paan chewing among adolescents (42), but this framework has not been tested. Three main intergenerational psychosocial transmission processes have been suggested: 1) Role modeling by children children try to imitate their parent which may lead to addiction; 2) Socialization of the child by the parent - parent-child interaction, social reinforcement, familial norms, easy access to the substance and parenting styles; 3) Genetic predisposition (11).

Looking at transmission of behaviour has the advantage of targeting modifiable factors as opposed to looking only at intergenerational transmission of genetic factors because behaviors are partially chosen while genes are not. Also, if compared to the transmission of education, intergenerational transmission of behaviour is less affected by family socioeconomic circumstances. Parental behaviour is crucial for its consequences on the development of children's behaviour resources along their life (19).

One of the pathways through which children acquire behaviors from their parents is explained by social learning theory (5). The child can initiate the habit by direct or indirect interaction with a parent. When children observe their parents' paan chewing, they may indirectly perceive the psychological and physiological rewards of the habit and this, coupled with children's natural tendency to imitate parents, can lead to initiation of the habit of paan chewing. At this phase, parental reinforcement can modify the child's behaviour; when the negative reinforcement is absent, the child assumes that the habit is acceptable in the family (6).

A recent systematic review on the social context of smokeless tobacco use summarized the themes which evolved from different qualitative studies assessing determinants of initiation. These themes explain other socio-cultural determinants, including familial positive norms and misbeliefs about beneficial effects of paan, as well as using children to purchase tobacco products for elders in the family which may induce curiosity and lead them to experimentation (10). All these processes are valid in paan chewing, but more longitudinal, genetic and qualitative studies are needed to fully understand these complex processes. 


\subsection{Knowledge translation}

Our results show that both the association of maternal and paternal habit of paan chewing with participant's paan chewing were statistically significant and similar. Moreover, only maternal strictness had a significant association with participant's paan chewing; this is understandable in a South Indian context where children are emotionally closer to their mother than to their father (43). These results may have a significant impact on policy development. Indeed, more effective targeted interventions could be planned by identifying high risk populations and including parents in the school-based programs, thereby interrupting the intergenerational transmission of the paan chewing habit. Similar interventions have been shown to be effective in the field of smoking prevention, where school-based buddy programs resulted in reducing smoking not only among kids but also their parents (44). Furthermore, studies have shown that the adolescents perceived such interventions as highly motivating (45).

Mass media campaigns tapping into the morality of a responsible parent have been taken up in many countries in regard to smoking, alcohol abuse and even road traffic awareness $(46,47)$. Similar campaigns could be effective in breaking the role modeling and socializing process in the intergenerational transmission of the paan chewing habit.

This study investigated maternal and paternal contributions to the intergenerational psychosocial transmission of paan chewing among South Indian subjects. The results suggest that the parental habit of paan chewing is a component of the complex shared social, genetic and environmental factors that contribute to an individual's paan chewing. Our findings support the need for multigenerational psychosocial intervention for effective prevention of paan chewing in this population.

\section{FUNDING:}

This work was supported by the Canadian Institutes of Health Research [MOP 81172, MOP=111207]; Ministère du Développement économique, de l'Innovation et de l'Exportation du Québec: Programme de soutien à la recherche (PSR), volet: Soutien à des initiatives internationales de recherche et d'innovation (SIIRI). M.-C. Rousseau is a recipient of a Career Award from the Fonds de Recherche du Québec - Santé. B. Nicolau holds a Canada Research Chair in Life Course Oral Epidemiology. S. Madathil is a recipient of bourse de maitrise et de doctorat from I.N.R.S-Institut Armand-Frappier du 2e et 3e cycles and Psychosocial Oncology Research Training (PORT) top up award. The funding sources did not have any role in study desing, collection, analysis, or interpretation of data including manuscript preparation.

6. CONFLICT OF INTEREST: None to declare. 


\section{References}

1. Mathers CD, Loncar D. Projections of global mortality and burden of disease from 2002 to 2030. PLoS Med. 2006;3(11):2011-30.

2. IIPS. Global Adult Tobacco Survey India 2009-2010 [Internet]. GATS. Deonar, Mumbai: International Institute for popuatlion sciences(IIPS); 2010. Available from: http://mohfw.nic.in/WriteReadData/l892s/1455618937GATS India.pdf

3. Monographs on the evaluation of carcinogenic risks to humans. A review of human carcinogens: Personal habits and indoor combustions. [Internet]. 100E ed. IARC [monograph online]. Lyon, France: IARC; 2012. p. 333-72. Available from: http://monographs.iarc.fr/ENG/Monographs/vol100E/

4. Pradeepkumar AS, Mohan S, Gopalakrishnan P, Sarma PS, Thankappan KR, Nichter M. Tobacco use in Kerala: findings from three recent studies. Natl Med J India. 2005;18(3):148-53.

5. Bandura A. Social learning theory. New York City: General Learning Press; 1977.

6. Akers RL, Lee G. A longitudinal test of social learning theory: adolescent smoking. J Drug Issues. 1996;26(2):317-43.

7. Van Schaik CP, Burkart JM. Social learning and evolution: the cultural intelligence hypothesis. Philos Trans R Soc Lond B Biol Sci. 2011 Apr 12;366(1567):1008-16.

8. Bantle C, Haisken JP. Smoke Signals: The Intergenerational Transmission of Smoking Behavior. Bound 2. 1974 Jan;3(1):45.

9. Oetting ER, Donnermeyer JF. Primary socialization theory: the etiology of drug use and deviance. I. Subst Use Misuse. 1998 Mar;33(4):995-1026.

10. Kakde S, Bhopal RS, Jones CM. A systematic review on the social context of smokeless tobacco use in the South Asian population : Implications for public health. Public Health. Elsevier Ltd; 2012;126(8):635-45.

11. Denise B K, Ping W. The contributions of mothers and fathers to the intergenerational transmission of cigarette smoking in adolescence. J Res Adolesc. 1995;5(2):225-52.

12. Corvo K, Carpenter EH. Effects of Parental Substance Abuse on Current Levels of Domestic Violence : A Possible Elaboration of Intergenerational Transmission Processes. 2000;15(2):123-36.

13. Palmer EJ, Hollin CR. Sociomoral Reasoning, Perceptions of Parenting and Self-reported Delinquency in Adolescents. Appl Cogn Psychol. 2001;15:85-100.

14. Singh V, Singh Z, Banerjee A, Basannar D. Determinants of smoking habit among medical students. Med J Armed Forces India. Director General, Armed Forces Medical Services; 2003 Jul;59(3):209-11.

15. White HR, Johnson V, Buyske S. Parental modeling and parenting behavior effects on offspring alcohol and cigarette use: a growth curve analysis. J Subst Abuse. 2000 Sep;12(3):287-310.

16. Wolin SJ, Bennett LA, Noonan DL, Teitelbaum MA. Disrupted family rituals; a factor in the intergenerational transmission of alcoholism. J Stud Alcohol. 1980 Mar;41(3):199_ 214.

17. Barnow S, Schuckit M, Lucht M, John U, Freyberger H-J. The Importance of a Positive Family History of Alcoholism, Parental Rejection and Emotional Warmth , Behavioral Problems and Peer Substance Use for Alcohol Problems in Teenagers : A Path Analysis. J Stud Alcohol. 2002;17:305-15. 
18. Vermeulen-Smit E, Koning IM, Verdurmen JEE, Van der Vorst H, Engels RCME, Vollebergh WAM. The influence of paternal and maternal drinking patterns within twopartner families on the initiation and development of adolescent drinking. Addict Behav. Elsevier Ltd; 2012 Nov;37(11):1248-56.

19. Cohen DA, Richardson J, LaBree L. Parenting behaviors and the onset of smoking and alcohol use: a longitudinal study. Pediatrics. 1994 Sep;94(3):368-75.

20. Smart RG, Gray G. Parental and peer influences as correlates of problem drinking among high school students. Int J Addict. 1979 Oct;14(7):905-17.

21. El-Amin SE-T, Nwaru BI, Ginawi I, Pisani P, Hakama M. The role of parents, friends and teachers in adolescents' cigarette smoking and tombak dipping in Sudan. Tob Control. 2011 Mar;20(2):94-9.

22. Ho C-S, Gee M-J. The parental influence of betel-chewing behavior among junior high school students in Taiwan. Subst Abus. 2002 Sep;23(3):183-9.

23. Boyle RG, Ph D, Claxton AMIJ, Forster JL. The Role of Social Influences and Tobacco Availability on Adolescent Smokeless Tobacco Use. 1997;(1):279-85.

24. Wang S-C, Tsai C-C, Huang S-T, Hong Y-J. Betel nut chewing: the prevalence and the intergenerational effect of parental behavior on adolescent students. J Adolesc Heal. 2004;34(3):244-9.

25. Serbin LA, Karp J. The intergenerational transfer of psychosocial risk: mediators of vulnerability and resilience. Annu Rev Psychol. 2004 Jan;55:333-63.

26. Albert I, Trommsdorff G, Mishra R. Parenting and adolescent attachment in India and Germany. Konstanz, Germany: Bibliothek der Universitat Konstanz; 2003. p. 97-108.

27. Berney LR, Blane DB. Collecting retrospective data: accuracy of recall after 50 years judged against historical records. Soc Sci Med. 1997 Nov;45(10):1519-25.

28. Parker G, Tupling H, Brown LB. A Parental Bonding Instrument. Br J Med Psychol. 1979 Mar 14;52(1):1-10.

29. Singh-manoux A, Fonagy P, Marmot M. The Relationship Between Parenting Dimensions and Adult Achievement : Evidence From the Whitehall II Study. Int J Behav Med. 2006;13(4):320-9.

30. Gopinathan Nair PR. Education and socio-economic changes in Kerala, 1793 - 1947. Soc Sci. 1976;4(8):28-43.

31. Royston P, White IR. Multiple imputaion by chained equation(MICE): Implementation in Stata. J Stat Softw. 2011;45(4).

32. Pearl J. Causal diagrams for empirical research. Biometrika. 1995;82(4):699-710.

33. Greenland S, Pearl J, Robins JM. Causal diagrams for epidemiologic research. Epidemiology. Jstor; 1999;10(1):37-48.

34. Shrier I, Platt RW. Reducing bias through directed acyclic graphs. BMC Med Res Methodol. 2008 Jan;8:70.

35. Stata data analysis and statistical software [Internet]. [computer program]. Texas, USA: StataCorp LP; 2012. Available from: http://www.stata.com/

36. Mullins LL, Wolfe-Christensen C, Pai ALH, Carpentier MY, Gillaspy S, Cheek J, et al. The relationship of parental overprotection, perceived child vulnerability, and parenting stress to uncertainty in youth with chronic illness. J Pediatr Psychol. 2007 Sep;32(8):97382.

37. O’Byrne KK, Haddock CK, Poston WSC. Parenting style and adolescent smoking. J Adolesc Health. 2002 Jun;30(6):418-25. 
38. Barnes GM, Reifman AS, Farrell MP, Dintcheff BA. The Effects of Parenting on the Development of A Six-Wave Alcohol Misuse : Adolescent Latent Growth Model. J marriage Fam. 2000;62(1):175-86.

39. Saraswathi TS, Pai S. Socialization in the Indian context. In: Kao HSR, Sinha D, editors. Cross-cultural research and methodology series. Thousand Oaks, CA, USA: Sage publications; 1997. p. 74-92.

40. Straus MA. Measuring Intrafamily Conflict Violence : The conflict tactics(CT) scales. J Marriage Fam. 1979;41(1):75-88.

41. Rao N, McHale JP, Pearson E. Links between socialization goals and child-rearing practices in Chinese and Indian mothers. Infant Child Dev. 2003 Dec;12(5):475-92.

42. Dongre A, Deshmukh P, Murali N, Garg B. Tobacco consumption among adolescents in rural Wardha: where and how tobacco control should focus its attention? Indian J Cancer. 2008;45(3):100-6.

43. Suppal P, Roopnarine JL. Paternal involvement in child care as a function of maternal employment in nuclear and extended families in India. Sex Roles. 1999 May;40(910):731-44.

44. Nilsson M, Stenlund H, Weinehall L, Bergström E, Janlert U. "I would do anything for my child, even quit tobacco": bonus effects from an intervention that targets adolescent tobacco use. Scand J Psychol. 2009 Aug;50(4):341-5.

45. Nilsson M, Weinehall L, Bergström E, Stenlund H, Janlert U. Adolescent's perceptions and expectations of parental action on children's smoking and snus use; national cross sectional data from three decades. BMC Public Health. BioMed Central; 2009 Jan;9:74.

46. Smoking Kid: Thai health foundation [Internet]. 2012. Available from: http://en.thaihealth.or.th/resource-center/media/474

47. National tobacco campaign -Break the Chain - Austrailian government [Internet]. Available from: http://quitnow.gov.au/internet/quitnow/publishing.nsf/Content/ntc-breaktvc 
Table 1: Percentage distribution of paan chewing in the HeNCe Life study (India: 2008-2012) and Global Adult Tobacco Survey (GATS) (India: 20092010)

\begin{tabular}{lll}
\hline & HeNCe (\%) & GATS (\%) \\
\hline Age range in years & 29 to 89 & 15 and above \\
Sex & & \\
Males & 55.2 & 51.7 \\
Females & 44.8 & 48.3 \\
& & \\
Participants' paan chewing & & \\
Never users & 83.7 & 86.5 \\
Past users & 6.9 & 2.8 \\
Current users & 9.4 & 10.7 \\
\hline
\end{tabular}


Table 2: Frequency distribution of selected potential confounders among control participants of the HeNCe Life study, Kerala, India (2008-2012)

\begin{tabular}{|c|c|c|}
\hline & $n(\%)^{a}$ & Missing (\%) \\
\hline \multicolumn{3}{|l|}{ Participant's measures } \\
\hline Mean age $\pm S D$, years & $59.86 \pm 11.8$ & \\
\hline \multicolumn{3}{|l|}{ Religion } \\
\hline Non-Hindu & $124(39.0)$ & \\
\hline Hindu & $194(61.0)$ & \\
\hline \multicolumn{3}{|l|}{ Education } \\
\hline Low education & $149(46.9)$ & \\
\hline High education & $169(53.1)$ & \\
\hline \multicolumn{3}{|l|}{ Smoking } \\
\hline Never & $185(58.2)$ & \\
\hline Ever & $133(41.8)$ & \\
\hline \multicolumn{3}{|l|}{ Alcohol consumption } \\
\hline Never & $263(82.7)$ & \\
\hline Ever & 55 (17.3) & \\
\hline
\end{tabular}

\section{Parental measures}

Maternal education

No formal education

$172(62.3)$

At least one year of formal education

$104(37.7)$

Paternal education

No formal education

117 (43.3)

At least one year of formal education

$153(56.7)$

Parent's socioeconomic position

LOW SEP

High SEP

$173(54.4)$

Maternal warmth index, mean \pm SD

$13.77 \pm 2.2$

Maternal strictness index, mean \pm SD

$4.09 \pm 1.4$

Paternal warmth index, mean \pm SD

$11.98 \pm 3.0$

Paternal strictness index, mean \pm SD

$4.58 \pm 1.6$

\footnotetext{
a Percentages, unless otherwise specified, among all valid responses

${ }^{\mathrm{b}}$ Percentages, unless otherwise specified, among all subjects included in the current analysis $(\mathrm{n}=318)$
} 
Table 3: Associations between parental and participants' habit of paan chewing

\begin{tabular}{|c|c|c|c|c|c|}
\hline & \multicolumn{2}{|c|}{ Participant's paan chewing } & \multirow{2}{*}{$\begin{array}{l}\text { Unadjusted } \\
\text { OR }(95 \% C I)\end{array}$} & \multirow{2}{*}{$\begin{array}{l}\text { Adjusted OR } \\
(95 \% \mathrm{CI})\end{array}$} & \multirow{2}{*}{$\begin{array}{c}\text { Fully adjusted OR } \\
(95 \% \mathrm{CI})\end{array}$} \\
\hline & $\begin{array}{c}\text { Never } \\
n=266 \\
n(\%)\end{array}$ & $\begin{array}{c}\text { Ever } \\
n=52 \\
n(\%)\end{array}$ & & & \\
\hline \multicolumn{6}{|c|}{$\begin{array}{l}\text { Maternal } \\
\text { paan chewing }\end{array}$} \\
\hline Never & $155(58.3)$ & $12(23.1)$ & 1 & 1 & 1 \\
\hline Ever & $111(41.7)$ & 40 (76.9) & $4.65(2.26-10.16)$ & $2.66(1.25-5.65)^{\mathrm{a}}$ & $2.40(1.11-5.21)^{\mathbf{b}}$ \\
\hline \multicolumn{6}{|c|}{$\begin{array}{l}\text { Paternal } \\
\text { paan chewing }\end{array}$} \\
\hline Never & $190(71.4)$ & 20 (38.5) & 1 & 1 & 1 \\
\hline Ever & $76(28.6)$ & 32 (61.5) & $4.00(2.06-7.84)$ & $2.93(1.44-5.95)^{\mathrm{c}}$ & $3.05(1.48-6.27)^{\mathbf{d}}$ \\
\hline
\end{tabular}


Fig 1: Conceptual model of the association between parents' and participant's paan chewing habit. The paths between shaded boxes are the associations of interest.

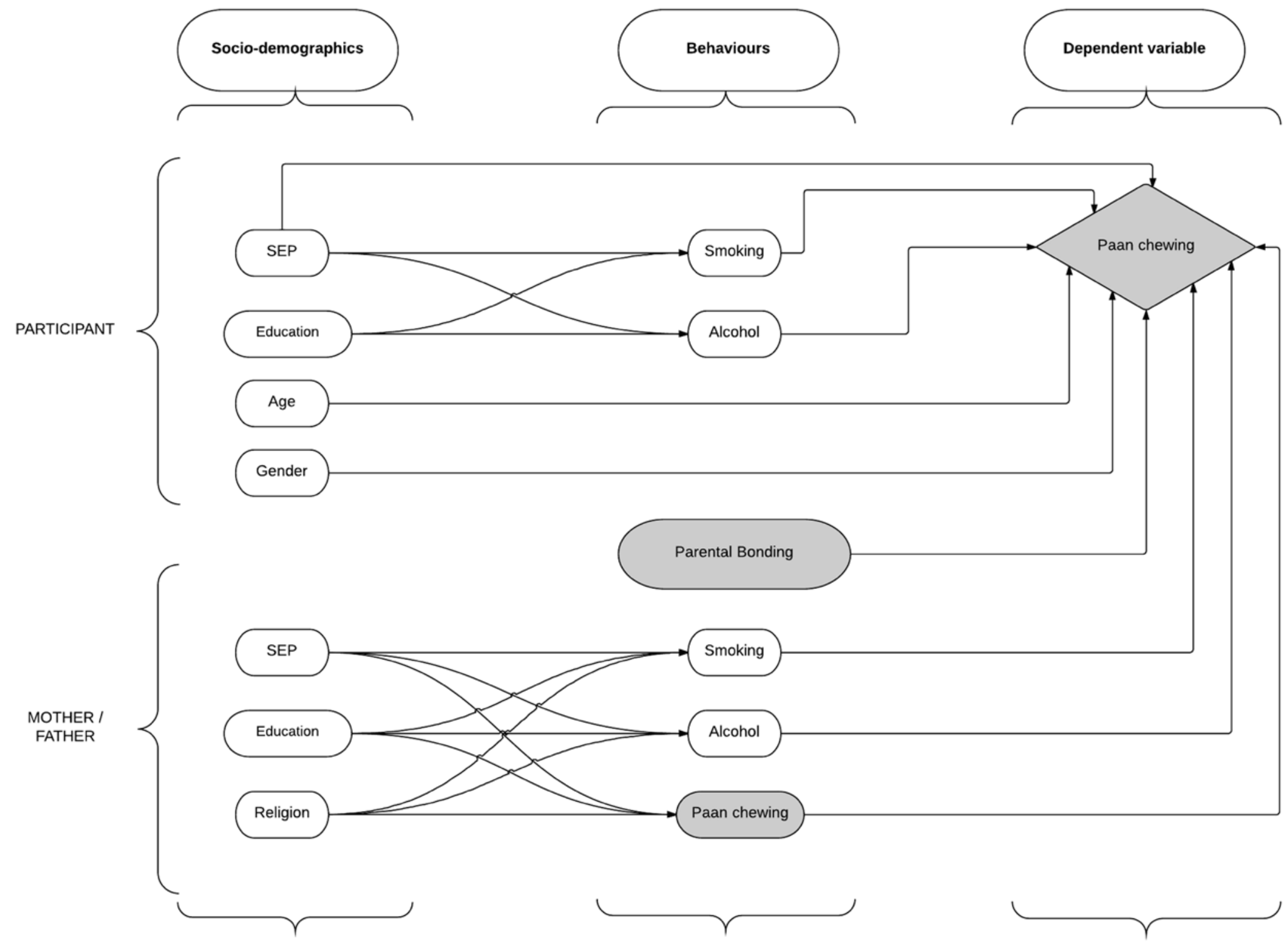




\section{Supplementary Material}

\section{Exploratory factor analysis of parental bonding instrument (PBI)}

To identify the latent constructs measured through a modified version of the Parental Bonding Instrument (PBI), an exploratory factor analysis was carried out separately for maternal and paternal parenting behaviors. (1) An oblimin rotation with delta 0 was applied and factors with an Eigenvalue $>1$ were retained.

Internal consistency of the instrument was assessed using Cronbach's alpha.(2) An alpha value between 0.7 to 0.8 shows satisfactory internal consistency of the instrument tested.(3) In our study both maternal and paternal parental bonding questionnaire showed satisfactory internal consistency $(0.754$ for maternal and 0.805 for paternal questionnaires). Cronbach's alpha values tend to be low if the number of questions is less or if they are measuring multiple dimensions.(2) We used a modified version of PBI with only 7 questions for each parent whereas the original PBI has shown to be measuring more than one dimension of parental bonding.(4,5) This may be one reason for moderate level of internal consistency of our instrument.

Table S1 shows the rotated pattern matrix for maternal and paternal instruments respectively. Both of them showed adequate Kaiser-Meyer-Olkin measure for sampling adequacy (0.731 for maternal and 0.805 for paternal instrument).(6) Only two factors had an Eigenvalue $>1$ for each parent. The combination of two factors explained for $65.3 \%$ and $73.8 \%$ of the variance in maternal and paternal measures respectively. The factor loadings were assessed using a rotated pattern matrix and factor loading plots (Figure S1 \& S2). All except two measures, (maternal (M7) and paternal expectation (F7)), where heavily loading heavily on either of the two latent factors.

To better interpret the latent constructs these two variables were dropped for further analyses. Measures loading on the same factor were combined together through simple summation to compute 'warmth' and 'strictness' variables for each parent. Although this is a non-refined method of creating factor scores, it has shown to be stable across different samples.(7) 
Table S1: Rotated factor loadings (pattern matrix) of maternal \& paternal bonding measures.

\begin{tabular}{|c|c|c|}
\hline Item & $\begin{array}{l}\text { Factor } 1^{\mathrm{a}} \\
\text { (Warmth) }\end{array}$ & $\begin{array}{l}\text { Factor } 2^{\mathrm{a}} \\
\text { (Strictness) }\end{array}$ \\
\hline \multicolumn{3}{|l|}{ Maternal } \\
\hline M1 - How much did she understand your problems and worried? & 0.8283 & \\
\hline M2 - How much could you confide in her about things that were bothering you? & 0.7058 & \\
\hline M3 - How much love and affection did she give you? & 0.8471 & \\
\hline M4 - How much time and attention did she give you when you needed it? & 0.8264 & \\
\hline M5 - How strict was she with the rules for you? & & 0.8676 \\
\hline M6 - How harsh was she when she punished you? & & 0.8286 \\
\hline M7 - How much did she expect you to do your best in everything you did? & 0.5664 & \\
\hline \multicolumn{3}{|l|}{ Paternal } \\
\hline F1 - How much did he understand your problems and worried? & 0.8396 & \\
\hline F2 - How much could you confide in him about things that were bothering you? & 0.8275 & \\
\hline F3 - How much love and affection did he give you? & 0.8824 & \\
\hline F4 - How much time and attention did he give you when you needed it? & 0.8614 & \\
\hline F5 - How strict was he with the rules for you? & & 0.8979 \\
\hline F6 - How harsh was he when he punished you? & & 0.9013 \\
\hline F7 - How much did he expect you to do your best in everything you did? & 0.7435 & \\
\hline
\end{tabular}

\footnotetext{
${ }^{\mathrm{a}}$ factor loadings $<0.4$ not shown
} 
Figure S1: Factor loading plot for maternal bonding measures

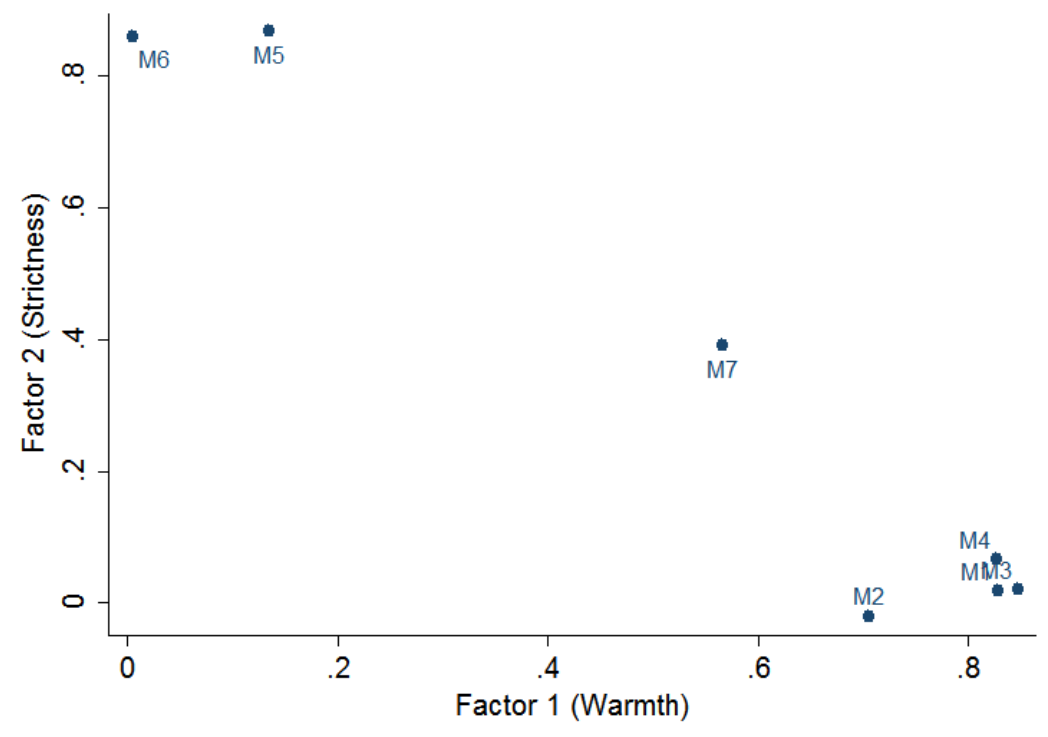

Figure S2: Factor loading plot for paternal bonding measures

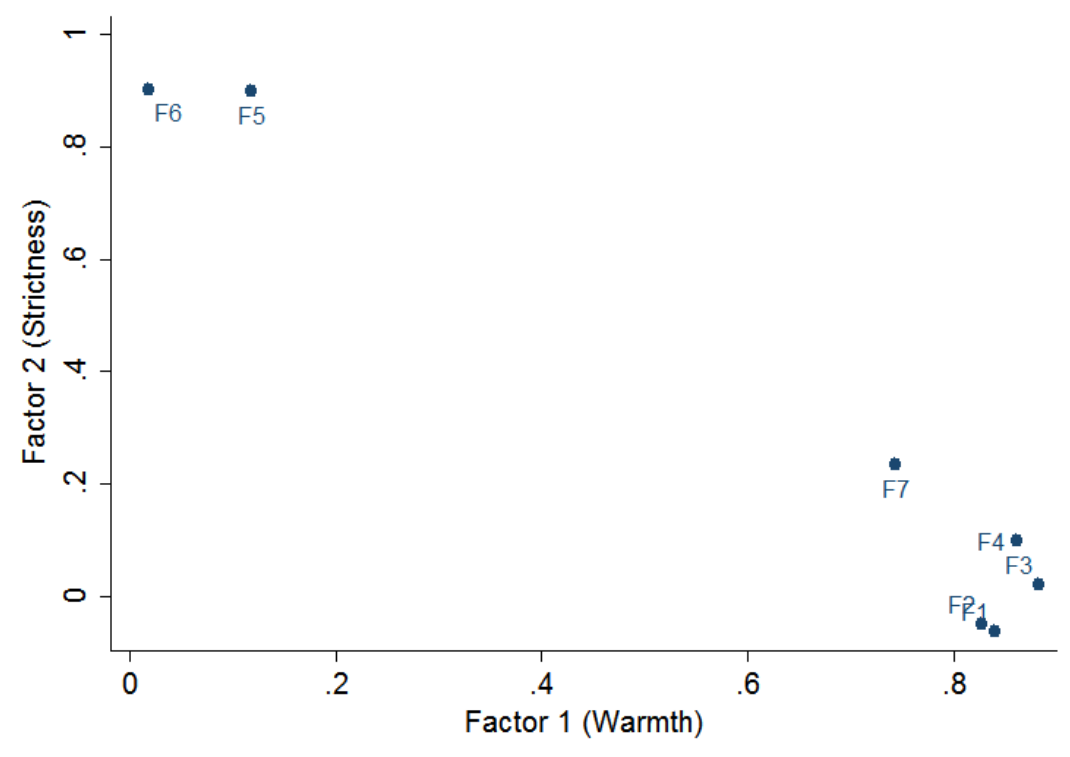




\section{Model selection using directed acyclic graph (DAG)}

Causal diagrams are a visual representation of the causal relationships between variables in a source population. Directed acyclic graphs (DAG) are a type of causal diagram introduced by Pearl in 1995.(8) DAGs based on a priori knowledge, are widely used to help plan data collection and analysis, in communicating results and to avoid pitfalls when selecting confounders. $(9,10)$ We used DAGs to identify the minimum set of confounders to be taken into account to estimate the true association between parental and participant's paan chewing (Figure S3).

Age, religious beliefs, parent's socio-economic position (SEP), parent's education, participant's smoking and alcohol consumption, and perceived parenting behaviors were identified as the minimum set of potential confounders to be included in the multivariate analyses. 
Figure S3: Directed acyclic graph (DAG) of the association between parents' and participants' paan chewing habit ${ }^{\mathrm{a}}$

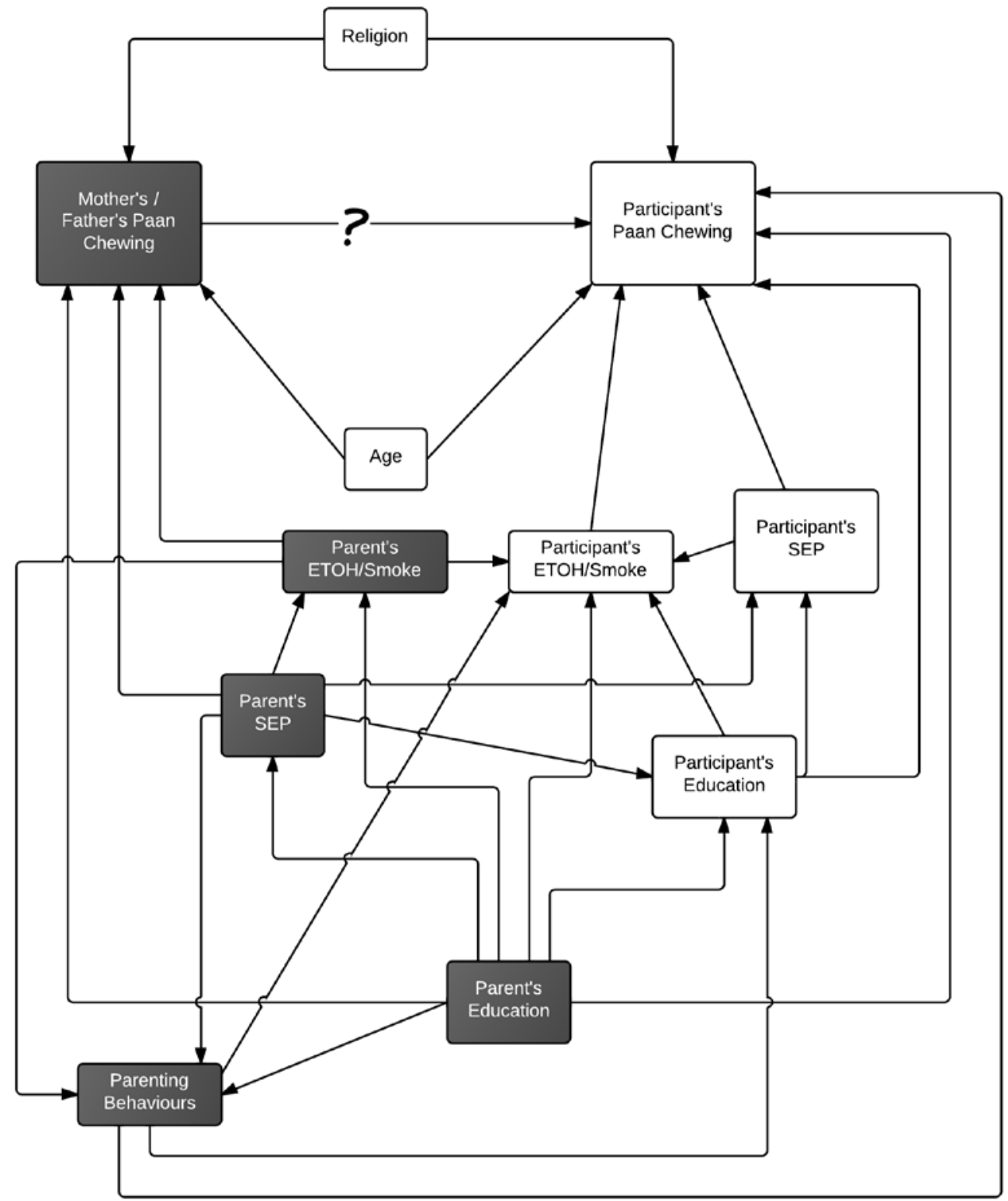

${ }^{\text {a }}$ The path with a question mark is the association of interest. Shaded boxes are parental variables and unshaded boxes are participant variables. 


\section{References}

1. Kim JO, Mueller CW. Introduction to factor analysis. What it is and how to do it. In: Uslaner EM, editor. Quantitaive Applications in the Social Science. Beverly Hills,California, USA: SAGE Publications; 1978.

2. Tavakol M, Dennick R. Making sense of Cronbach’s alpha. Int J Med Educ. 2011 Jun 27;2:53-5.

3. Bland JM, Altman DG. Cronbachs alpha BMJ. Br Med J. 1997;314:572.

4. Murphy E, Brewin CR, Silka L. The assessment of parenting using the Parental Bonding Instrument: two or three factors? Psychol Med. 1997 Mar;27(2):333-42.

5. Parker G. The parental bonding instrument. Soc Psychiatry Psychiatr Epidemiol. 1990;25(6):281-2.

6. Dziuban CD, Shirkey EC. When is a correlation matrix appropriate for factor analysis? Some decision rules. Psychol Bull. 1974;81(6):358-61.

7. Distefano C, Zhu M, Mîndril D. Understanding and Using Factor Scores : Considerations for the Applied Researcher. Pract assessment, Res Eval. 2009;14(20).

8. Pearl J. Causal diagrams for empirical research. Biometrika. 1995;82(4):699-710.

9. Greenland S, Pearl J, Robins JM. Causal diagrams for epidemiologic research. Epidemiology. Jstor; 1999;10(1):37-48.

10. Shrier I, Platt RW. Reducing bias through directed acyclic graphs. BMC Med Res Methodol. 2008 Jan;8:70. 